\title{
Role of Endothelial-Leukocyte Adhesion Molecule 1 (ELAM-1) in Neutrophil-mediated Lung Injury in Rats
}

\author{
Michael S. Mulligan, James Varani, Michael K. Dame, Caryl L. Lane, ${ }^{\star}$ C. Wayne Smith, $\neq$ \\ Donald C. Anderson, ${ }^{* *}$ and Peter A. Ward \\ Department of Pathology, University of Michigan Medical School, Ann Arbor, Michigan 48109; and *Department of Pediatrics \\ and ${ }^{\ddagger}$ Departments of Cell Biology and Microbiology and Immunology, Baylor College of Medicine, Houston, Texas 77054
}

\begin{abstract}
Two murine monoclonal antibodies (CL-3 and CL-37, both $\left.\mathbf{F}\left(\mathbf{a b}^{\prime}\right)_{2}\right)$ to human endothelial-leukocyte adhesion molecule-1 (ELAM-1) were found to react immunohistochemically with rat pulmonary artery endothelial cells that had been pretreated with tumor necrosis factor (TNF $\alpha$ ). CL-3, but not CL-37, blocked in vitro adherence of neutrophils to TNF $\alpha$-treated endothelial cells and the killing of TNF $\alpha$-treated rat endothelial cells by phorbol ester activated neutrophils. In rats treated systemically with CL-3, there was a $70 \%$ reduction in accumulation of neutrophils in glycogen-induced peritoneal exudates. Treatment of animals with CL-37 anti-ELAM-1 did not reduce neutrophil accumulation under the same conditions. When IgG immune complex deposition was induced in dermis and in lungs of rats, treatment with CL-3 anti-ELAM-1 markedly reduced vascular injury as measured by changes in vascular permeability (leakage of ${ }^{125} \mathrm{I}$-albumin) and hemorrhage (extravasation of ${ }^{51} \mathrm{Cr}$-red blood cells). The protective effects of CL-3 antiELAM-1 were related to greatly diminished recruitment of neutrophils (as assessed morphologically, by tissue extraction of myeloperoxidase, and by retrieval, via bronchoalveolar lavage, of neutrophils from lung). CL-37 had no protective effects in vivo after deposition of immune complexes in lung. Using either CL-3 or CL-37 anti-ELAM-1, immunohistochemical analysis of lungs undergoing IgG immune complex-induced injury revealed a striking upregulation of ELAM-1 in the lung vasculature (venules and interstitial capillaries), with a peak intensity developing between 3 and $4 \mathrm{~h}$ after deposition of immune complexes in lung. Vascular beds of spleen, liver, and kidney failed to show upregulation of ELAM-1 under these same conditions. The immunohistochemical reactivity of rat lung was abolished if the anti-ELAM-1 preparation was first absorbed with monolayers of human umbilical vein endothelial cells that had been pretreated with TNF $\alpha$. Untreated human endothelial cells failed to cause loss of lung reactivity of the anti-ELAM-1 preparation. These data indicate that ELAM-1 is upregulated in the pulmonary vasculature of rats during deposition of immune complexes and that ELAM-1 appears to play an obligate role in the recruitment of neutrophils. (J. Clin. Invest. 1991. 88:13961406.) Key words: endothelial cells $\bullet$ tumor necrosis factor $\alpha \bullet$ immune complexes $\bullet$ endothelial leukocyte adhesion molecule$1 \cdot$ neutrophils
\end{abstract}

Address correspondence to Peter A. Ward, M.D., Professor and Chairman, University of Michigan Medical School, Department of Pathology, 1301 Catherine Street, Box 0602, Ann Arbor, MI 48109-0602.

Received for publication 20 February 1991 and in revised form 3 June 1991.

\section{J. Clin. Invest.}

(C) The American Society for Clinical Investigation, Inc.

$0021-9738 / 91 / 10 / 1396 / 11 \quad \$ 2.00$

Volume 88, October 1991, 1396-1406

\section{Introduction}

Adhesion molecules appear to play critical roles in the recruitment of neutrophils to sites of inflammation. The need for the CD18 integrins is most clearly shown by the fact that neutrophil accumulation at sites of bacterial infection is profoundly reduced in patients with CD18 deficiency (1). The use of murine MAbs to CD18 and to intercellular adhesion molecule-1 (anti-ICAM-1) ${ }^{1}$ in various animal models has also demonstrated that CD18 integrins and ICAM-1 are required for neutrophil accumulation at inflammatory sites (2-4). However, recent evidence indicates that $\mathrm{CD} 18$-independent mechanisms are also linked to emigration of neutrophils in some inflammatory conditions involving the lung $(2,5)$. Results from studies in vitro indicate that $\mathrm{CD} 18$-independent neutrophil-endothelial adhesion may involve members of the lectin cellular adhesion molecule (LEC-CAM) (Selectin) family of adhesion molecules (6-11). While there are no published studies in vivo showing that endothelial-leukocyte adhesion molecule-1 (ELAM-1) and granular membrane protein-140 (GMP-140) are involved in neutrophil localization, Jutila et al. (12) have shown that a MAb (MEL-14) to a third member of the LECCAM family, LEC-CAM-1 leukocyte adhesion molecule-1 (LAM-1), in the mouse markedly reduces the number of neutrophils in experimental peritoneal inflammation.

This study addresses the hypothesis that ELAM-1 may play a role in the localization of neutrophils at sites of acute imflammation. The experiments involve the evaluation of two antihuman ELAM-1 immune monoclonal antibodies (CL-3 and CL-37) that cross-react with an antigen expressed on cultured, tumor necrosis factor (TNF) $\alpha$-stimulated rat pulmonary artery endothelial cells. Evidence is provided that these antibodies recognize rat ELAM-1 at sites of acute inflammation, and that one of the MAbs (CL-3) greatly diminishes that accumulation of neutrophils and attenuates the injury after deposition of IgG immune complexes in the rat lung and skin.

\section{Methods}

Reagents. Unless otherwise indicated, all reagents were purchased from Sigma Chemical Co., St. Louis, MO.

Monoclonal antibodies. Antibodies directed against ELAM-1 were generated by immunization of BALB/c mice with human umbilical vein endothelial cells (HUVEC) which had been stimulated with recombinant human IL- $1 \beta$ for $3 \mathrm{~h}$ at $37^{\circ} \mathrm{C}$. Mouse hybridomas were prepared in the usual manner (13), and supernatant fluids containing IgG were screened for their ability to react exclusively with stimulated (IL-1 $\beta, 4$ h, $37^{\circ} \mathrm{C}$ ) HUVEC, using immunoperoxidase technology. Three hybrid-

1. Abbreviations used in this paper: ANOVA, analysis of variance; ELAM-1, endothelial-leukocyte adhesion molecule 1; HUVEC, human umbilical vein endothelial cells; ICAM-1, intercellular adhesion molecule 1; LEC-CAM, lectin cellular adhesion molecule; MPO, myeloperoxidase; RBC, red blood cells; RPAEC, rat pulmonary artery endothelial cells; TNF $\alpha$, tumor necrosis factor $\alpha$. 
omas, CL-2, CL-3, and CL-37 (all IgG 1 ) were subcloned. These antibodies partially inhibited binding of human neutrophils to IL-1 $\beta$ stimulated permeability and reacted (as assessed by flow cytometry) with COS and L cells transfected with CDNA for ELAM-1 but not with cells transfected with irrelevant cDNA (Kishimoto, K. I., and C. W. Smith, unpublished data). The ELAM-1 CDNA in the CDM8 expression vector (14) was kindly provided by Dr. B. Seed (Harvard University, Boston, MA). The MAbs exhibited little or no reactivity (by immunoperoxidase) with unstimulated HUVEC, bound maximally to HUVEC stimulated by IL- $1 \beta$ for $4 \mathrm{~h}$, and exhibited little reactivity with stimulated HUVEC at $24 \mathrm{~h}$. None of the MAbs bound to human or rat platelets, neutrophils, monocytes, or lymphocytes as determined by flow cytometry (data not shown). Furthermore, as assessed by flow cytometric analysis, CL-3 anti-ELAM-1 failed to react either with ADP-stimulated rat platelets or with $N^{\prime}$-FMLP-stimulated rat blood neutrophils (data not shown). $\mathrm{F}\left(\mathrm{ab}^{\prime}\right)_{2}$ preparations were made using the ImmunoPure $\mathrm{F}\left(\mathrm{ab}^{\prime}\right)_{2}$ preparation kit (Pierce Chemical Co., Rockford, IL).

The control (irrelevant) monoclonal antibody consisted of $\mathrm{F}\left(\mathrm{ab}^{\prime}\right)_{2}$ fragments derived from pepsin digestion of MOPC 21 (mouse myeloma, $\operatorname{IgG}_{1}$ ). For the immune complex studies of lung and dermal vascular injury, a total of $135 \mu \mathrm{g}$ anti-ELAM-1 (CL-3 and 37) or irrelevant $F\left(a b^{\prime}\right)_{2}$ was injected intravenously in three equally divided doses at 2.5, 3.0, and 3.5 h after intravenous injection of BSA and intratracheal instillation or intradermal injection of anti-BSA (which consisted of rabbit polyclonal IgG rich in antibody to bovine serum albumin, antiBSA). Unless otherwise noted, negative control animals were injected intradermally or intratracheally with anti-BSA, but the intravenous injection of BSA was omitted.

Animal models of immune complex alveolitis and dermal vasculitis. Rabbit polyclonal IgG rich in anti-BSA was used to induce lung and dermal vascular injury (15). IgG was purchased from Organon Teknika, West Chester, PA). The IgG anti-BSA and BSA (Sigma Chemical Co., St. Louis, MO) preparations that were used for injection into rats contained $20 \mathrm{pg} / \mathrm{ml}$ and $12 \mathrm{pg} / \mathrm{ml}$ of endotoxin activity, respectively, as measured by the limulus amebocyte lysate assay (E-toxate, Sigma Chemical Co.). 300-350 g male Long-Evans specific pathogen-free rats (Charles River Breeding Laboratories, Inc., Wilmington, MA) were used for all studies. Intraperitoneal ketamine $(25-50 \mathrm{mg} / 100 \mathrm{~g}$ body $\mathrm{wt})$ and sodium pentobarbital $(5 \mathrm{mg} / 100 \mathrm{~g}$ body $\mathrm{wt})$ were administered for sedation and anesthesia. Immune complex lung injury was induced by the intravenous injection of $10 \mathrm{mg} \mathrm{BSA}$ (in $1.0 \mathrm{ml}$ saline) and the intratracheal instillation of anti-BSA in $300 \mu \mathrm{l}$. The following intratracheal doses of anti-BSA were used: $0.75 \mathrm{mg}, 1.50 \mathrm{mg}, 2.50 \mathrm{mg}$, or 3.33 $\mathrm{mg}$. Rats were killed $4 \mathrm{~h}$ after injury and the pulmonary circulation was flushed with $10 \mathrm{ml}$ saline via pulmonary arterial injection. Permeability indices, as a measure of lung injury, were determined by comparing leakage of ${ }^{125}$ I-labeled albumin into lung parenchyma to the amount remaining in $1.0 \mathrm{ml}$ of blood. Reversed passive dermal Arthus reactions were induced by intradermal injection of $0.10-0.84 \mathrm{mg}$ anti-BSA contained in a volume of $0.10 \mathrm{ml}$, followed by intravenous injection of $10 \mathrm{mg} \mathrm{BSA}$ in $1.0 \mathrm{ml}$ saline. Rats were killed $4 \mathrm{~h}$ thereafter and permeability indices calculated by measuring the ratio of radioactivity present in full thickness skin biopsies compared to radioactivity present in $\mathbf{1 . 0}$ $\mathrm{ml}$ of blood. Negative controls included animals with intradermal sites injected with anti-BSA but with the omission of intravenous injection of BSA.

For assessment of lung or dermal hemorrhage, red blood cells (RBC) were harvested from heparinized blood obtained from normal adult Long-Evans rats. $9 \mathrm{ml}$ blood was diluted with $40 \mathrm{ml}$ saline containing 1:1,000 heparin. To this was added $100 \mu \mathrm{Ci}{ }^{51} \mathrm{Cr}$, followed by incubation for $1 \mathrm{~h}$ at $37^{\circ} \mathrm{C}$ with continuous shaking. After centrifugation at $1,000 \mathrm{rpm}\left(\right.$ at $4^{\circ} \mathrm{C}$ ) for $6 \mathrm{~min}$, cells were washed in PBS three times and were then ready for use. The same injury and treatment protocols were used as described above for immune complex-induced lung and skin injury. Animals were injected with ${ }^{51} \mathrm{Cr}$-labeled RBC (45 $\mu \mathrm{l}$ containing $80,000 \mathrm{cpm}$ ) $1 / 2 \mathrm{~h}$ before injection of BSA and anti-BSA. At the time of killing, skin sites and saline-perfused lungs were mea- sured for ${ }^{51} \mathrm{Cr}$ radioactivity and compared to counts present in $1.0 \mathrm{ml}$ of blood. At the conclusion of each experiment, blood samples from each animal were centrifuged and radioactivity measured in the cells and serum. No radioactivity counts above background levels were detected in the sera from animals injected with ${ }^{51} \mathrm{Cr}$ RBC (data not shown).

Glycogen-induced peritoneal exudates. Neutrophil-rich exudates were elicited in rat peritoneal cavities with the injection of $25 \mathrm{ml} 0.1 \%$ (wt/vol) oyster glycogen $4 \mathrm{~h}$ before killing. $135 \mu \mathrm{g} \mathrm{F}\left(\mathrm{ab}^{\prime}\right)_{2}$ anti-ELAM1 , was injected intravenously in three equally divided doses in the treatment group (at 2.5, 3.0, and $3.5 \mathrm{~h}$ ) to assess effects on neutrophil recruitment into peritoneal cavities.

Tissue myeloperoxidase (MPO) content. A standard reference curve was first established by measuring MPO in lungs and skin sites that had been injected with known numbers of neutrophils. For our studies, lung and skin sites were extracted by homogenization and sonication procedures that have been previously described (16). MPO activity in supernatants was measured by the change in optical density (at 460 $\mathrm{nm}$ ) resulting from decomposition of $\mathrm{H}_{2} \mathrm{O}_{2}$ in the presence of $o$-dianisidine.

Immunohistochemical analysis of cells and lung tissue. Monolayers of rat pulmonary artery endothelial cells (RPAEC) on plastic slides were stimulated with $50 \mathrm{ng} / \mathrm{ml}$ human recombinant TNF $\alpha$ for $4 \mathrm{~h}$, washed with PBS, and fixed with acetone. Slides containing monolayers of stimulated or unstimulated cells were then incubated with CL-3 or CL-37 anti-ELAM-1 $(1.0 \mathrm{ng} / \mathrm{ml})$ for $45 \mathrm{~min}$. The slides were then washed with PBS and then stained for bound MAb using the biotin/avidin-peroxidase system for mouse IgG (Vectastain; Vector Laboratories Inc., Burlingame, CA). After hematoxylin counterstaining, sections were coated with aqua-mount (Lerner Laboratories, Pittsburgh, PA) and examined by light microscopy for the presence of reaction products of peroxidase. Immune complex-induced lung injury was accomplished using the same protocols described above. Animals were killed at $0,1,2,3$, and $4 \mathrm{~h}$. The lungs were inflated with 8-9 $\mathrm{ml}$ of optimal cutting temperature (OCT) compound (Miles Laboratories Inc., Elkhart, IN) and frozen sections obtained from lungs of normal rats and those undergoing intraalveolar deposition of immune complexes. After mounting on poly-L-lysine coated slides and fixation with acetone, tissue sections were then reacted with the anti-ELAM-1 preparation, as described above.

An additional experiment was also carried out using the same staining procedure, and using lung from the 4-h immune complex reaction. Before use, the CL-3 preparation $(1.0 \mathrm{ng} / \mathrm{ml})$ was incubated for $1 \mathrm{~h}$ at $27^{\circ} \mathrm{C}$ with monolayers $\left(5 \times 10^{6}\right.$ cells $)$ of TNF $\alpha-(50 \mathrm{ng} / \mathrm{ml})$-stimulated or unstimulated HUVEC, preceding application of antibody to the lung sections. This was done to assess whether TNF $\alpha$-stimulated HUVEC would remove antibody reactivity.

Morphologic evaluation of lungs and skin. Lungs were fixed in $10 \%$ phosphate buffered formalin for subsequent hematoxylin and eosin staining and examination by light microscopy. Skin samples were similarly treated.

Neutrophil-mediated cytotoxicity of endothelial cells. Neutrophilmediated cytotoxicity of RPAEC was measured by a standard ${ }^{51} \mathrm{Cr}$ release assay (17). RPAEC were seeded into a 24-well culture dish, with $5 \times 10^{4}$ cells per well in $1 \mathrm{ml}$ culture medium. Each well received $2 \mu \mathrm{Ci}$ of $\mathrm{Na}^{51} \mathrm{CrO}_{4}$ (New England Nuclear, Boston, MA) and the monolayers were then incubated for $14 \mathrm{~h}$. TNF $\alpha$ was then added at a concentration of $50 \mathrm{ng} / \mathrm{ml}$ and monolayers were incubated for an additional $4 \mathrm{~h}$. The plates were then washed twice with HBSS containing $0.02 \%$ BSA to remove the nonincorporated radioactivity. The endothelial cell monolayers were then ready for use. When antibodies (CL-2, CL-3, CL-37 MAbs) were employed, they were added to the monolayers and incubated for $30 \mathrm{~min}$. Human blood neutrophils were isolated (see below) and suspended in HBSS supplemented with $0.02 \%$ BSA. Neutrophils were then added to duplicate wells to give effector to target cell ratios of $30: 1$ in a final volume of $1.0 \mathrm{ml}$. Neutrophils were allowed to settle onto the endothelial cell monolayers for $30 \mathrm{~min}$ before the addition of phorbol myristate acetate (PMA) $(50 \mathrm{ng} / \mathrm{ml})$ which was added in a volume of $0.1 \mathrm{ml}$ per well. After an additional incubation at $37^{\circ} \mathrm{C}$ for $6 \mathrm{~h}, 0.9$ 
ml supernatant was removed from each well and any cells in suspension removed by centrifugation. The supernatant fluid $(0.5 \mathrm{ml})$ was aspirated and assayed in a $\gamma$-scintillation counter to determine ${ }^{51} \mathrm{Cr}$ release. Spontaneous release was determined using fluids from wells receiving medium only. Total release of ${ }^{51} \mathrm{Cr}$ was achieved by addition of $0.2 \%$ Triton $\mathrm{X}-100$. The median spontaneous release never exceeded $20 \%$ of the total release and in most experiments ranged between 5 and $15 \%$ of the total release. The cytotoxicity was calculated by the following formula:

$$
\% \text { cytotoxicity }=\frac{\text { experimental release }- \text { spontaneous release }}{\text { total release }- \text { spontaneous release }} \times 100 \text {. }
$$

Isolation of blood neutrophils. Heparinized whole blood (rat or human) diluted 1:1 with PBS was layered onto Ficoll-Hypaque (specific gravity 1.077), centrifuged $(400 \mathrm{~g}, 30 \mathrm{~min})$ and the red blood cell layer containing the neutrophils incubated in a lysing solution of $\mathrm{NH}_{4} \mathrm{Cl}$ (17). The neutrophils were then washed and resuspended in HBSS. Differential counts using crystal violet staining of the nuclei revealed that $>95 \%$ of the cells were neutrophils. Neutrophils were then stimulated in vitro with FMLP $(100 \mathrm{nM})$, immune complexes (containing 15 $\mu \mathrm{g}$ antibody/ml), or PMA $(20 \mathrm{ng} / \mathrm{ml})$, and the $\mathrm{O}_{2}^{-}$responses measured by superoxide dismutase-inhibitable reduction of ferricytochrome $c$. In the case of stimulation of rat neutrophils with FMLP or immune complexes, cytochalasin B (Sigma Chemical Co.) was added $(5 \mu \mathrm{g} / \mathrm{ml})$ to accentuate the $\mathrm{O}_{2}^{-}$responses (18).

Rat neutrophils were also used to examine the effects of CL-3 antiELAM-1 on neutrophil chemotactic responses using the leading front method for quantitation (19). FMLP $\left(10^{-8} \mathrm{M}\right)$ and HBSS were used for positive and negative control attractants, respectively. CL-3 antiELAM-1 $(7 \mu \mathrm{g} / \mathrm{ml})$ was added to the neutrophil suspension, as indicated, to test its effects on migratory responses of rat neutrophils.

Statistical analysis. The data were analyzed by one or two-way analysis of variance (ANOVA) for complete data sets from each individual experiment. Significant differences were then analyzed comparing individual group means using unpaired Student's $t$ test. Statistical significance was defined as $P<.05$. Details of each analysis are contained in the figure legends. All values are expressed as mean \pm SEM unless otherwise indicated.

\section{Results}

Protection by anti-ELAM-1 against neutrophil-mediated killing of rat pulmonary artery endothelial cells. Both $\mathrm{F}\left(\mathrm{ab}^{\prime}\right)_{2} \mathrm{CL}-3$ and CL-37 anti-ELAM-1 were evaluated for their effects on adhesion of human neutrophils to RPAEC that had first been exposed for $4 \mathrm{~h}$ to human recombinant TNF $\alpha(50 \mathrm{ng} / \mathrm{ml})$. After washing, irrelevant $\mathrm{F}\left(\mathrm{ab}^{\prime}\right)_{2}$ or CL-3 or CL-37 anti-ELAM$1\left(\mathrm{~F}\left(\mathrm{ab}^{\prime}\right)_{2}\right)$ were added $(50 \mu \mathrm{g} / \mathrm{ml})$ for $1 \mathrm{~h}$ at $37^{\circ} \mathrm{C}$, washed, and then human neutrophils were added. Nonattached neutrophils were removed by washing and counted and the percentage of attached neutrophils calculated. TNF $\alpha$ treatment of endothelial cells with no further treatment caused the adherence values (\% of total cells) to rise from $27 \pm 3$ to $60 \pm 3$. The presence of CL-3 caused a $48 \pm 1 \%$ reduction in adherence interactions of neutrophils to endothelial cells, while the presence of CL-37 caused only a $17 \pm 1 \%$ reduction in adherence interactions of neutrophils with TNF $\alpha$-treated endothelial cells. These results suggested that under the conditions used adherence of neutrophils to TNF $\alpha$-treated RPAEC involves an ELAM-1 epitope that is more effectively blocked by CL-3 as compared to CL-37.

Based on these findings, we evaluated the abilities of $\mathrm{F}\left(\mathrm{ab}^{\prime}\right)_{2}$ MAbs to ELAM-1, namely CL-2, CL-3, and CL-37, to alter the cytotoxic effects on RPAEFC of phorbol ester (PMA)-stimulated human neutrophils. Although both rat and human neu-
Table I. Effects of Anti-ELAM-1 on Human Neutrophil-Mediated Killing of Rat Pulmonary Artery Endothelial Cells

\begin{tabular}{lc}
\hline Treatment* & $\begin{array}{c}\text { Protection (percent reduction } \\
\text { in }{ }^{\text {s1 }} \text { Cr release) }\end{array}$ \\
\hline CL-2 & $<1.0$ \\
CL-3 & $78 \pm 5$ \\
CL-37 & $<1.0$
\end{tabular}

* All monoclonal antibodies to human ELAM-1 were $\mathrm{F}\left(\mathrm{ab}^{\prime}\right)_{2}$ of murine $\mathrm{IgG}_{1}$. Rat pulmonary artery endothelial cells were pretreated with TNF $\alpha$ as described in the text. Each antibody was examined in at least two separate experiments and yielded similar results. Actual values for specific ${ }^{51} \mathrm{Cr}$ release (percent) from endothelial cells were: negative control (nonstimulated neutrophils), 12 1 ; positive control (phorbol ester stimulated neutrophils), $68 \pm 3$; positive control in presence of CL-3, $24 \pm 1 .{ }^{\ddagger}$ Protection percent was calculated as 1.0 minus the ratio of treated and untreated cells (from which negative control values were subtracted) times 100 .

trophils stimulated with PMA bring about the killing of RPAEC, human neutrophils are much more effective in the killing process which correlates with a greater oxygen radical burst (by more than twofold) in human neutrophils as compared to rat neutrophils (17). For this reason, human neutrophils were used in the following experiments. Pretreatment of endothelial cells (RPAEC) with TNF $\alpha$ not only increases the adherence interactions with human neutrophils but also greatly accentuates the killing of the endothelial cells by activated neutrophils (20). The cytotoxic effects on these endothelial cells are known to be related to the generation by neutrophils of toxic oxygen products (17). MAbs (CL-2, CL-3, CL-37) were used at a final concentration of $15 \mu \mathrm{g} / \mathrm{ml}$ and were added to the endothelial cell monolayers immediately before addition of human neutrophils. The endpoint was release of ${ }^{51} \mathrm{Cr} 4 \mathrm{~h}$ later from the endothelial cells which had been previously exposed to TNF $\alpha(50 \mathrm{ng} / \mathrm{ml})$ for $4 \mathrm{~h}$ before washing and addition of neutrophils and PMA $(20 \mathrm{ng} / \mathrm{ml})$. As is evident from the data in Table I, only CL-3 antibody to human ELAM-1 was able to suppress the cytotoxic effects of activated neutrophils (by $\sim 80 \%$ ). As will be shown below, using immunoperoxidase techniques, CL-3 and CL-37 were equally reactive with rat pulmonary artery endothelial cells that had been pretreated with TNF $\alpha$ and also reacted with lung tissue sections $4 \mathrm{~h}$ after in vivo deposition of immune complexes.

Inhibition by anti-ELAM-1 of neutrophil accumulation in glycogen-induced peritoneal exudates. Neutrophil-enriched exudates (containing $>90 \%$ neutrophils) were induced in rat peritoneal cavities by the injection $4 \mathrm{~h}$ earlier of $0.1 \%$ (wt/vol) oyster glycogen in PBS. When employed, $\mathrm{F}\left(\mathrm{ab}^{\prime}\right)_{2} \mathrm{CL}-3$ or CL37 anti-ELAM-1 was injected intravenously in three equally divided doses (45 $\mu \mathrm{g} \mathrm{each}$ ) at $2.5,3.0$, and $3.5 \mathrm{~h}$. As is evident by the data in Fig. 1, there was a significant reduction (70\%) in numbers of neutrophils accumulating in the peritoneal cavities of rats treated with CL-3 anti-ELAM-1 as compared to those animals treated with irrelevant $\mathrm{F}\left(\mathrm{ab}^{\prime}\right)_{2}$ ("positive control" group) (Fig. 1). The negative control group consisted of rats that had been intraperitoneally injected with saline (in the absence of glycogen) into the peritoneal cavity and then treated with irrelevant $F\left(a b^{\prime}\right)_{2}$. As expected, few neutrophils were recruited under these conditions. Treatment of rats with CL-37 


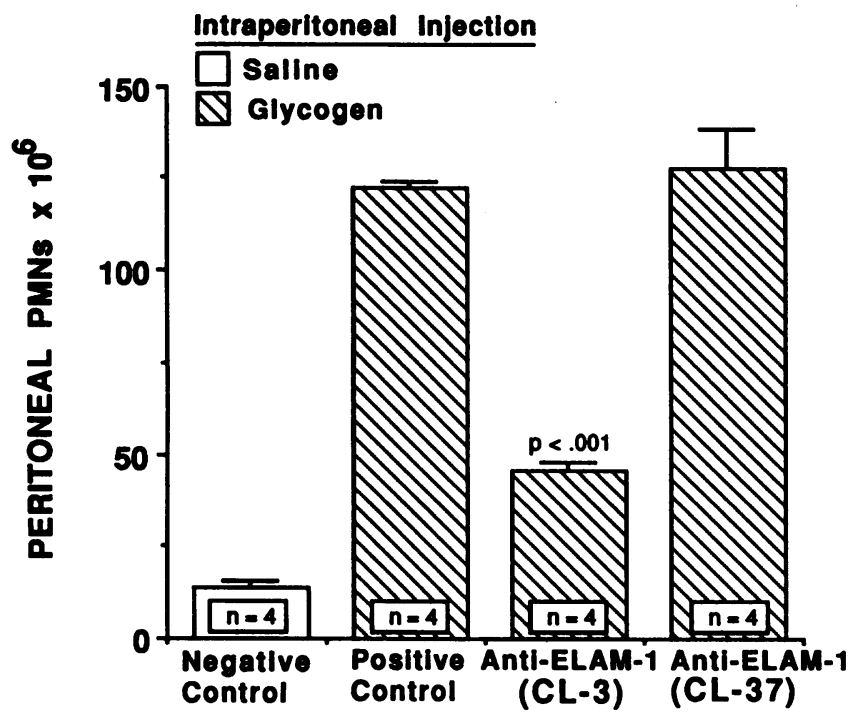

Figure 1. Effects of treatment of rats with $\mathrm{F}\left(\mathrm{ab}^{\prime}\right)_{2}$ anti-ELAM-1 (CL-3 and CL-37) on accumulation of neutrophils (PMN) after intraperitoneal instillation of glycogen. Cells were harvested at $4 \mathrm{~h}$. The negative control rat was injected intraperitoneally with sterile saline. The positive controls were treated with irrelevant $\mathrm{F}\left(\mathrm{ab}^{\prime}\right)_{2}$ or anti-ELAM-1 preparations. The data were analyzed with a one-way ANOVA $(P$ $<0.001$ ), the positive antibody and the negative controls demonstrating $P<0.001$. For comparison of the anti-ELAM-1 to the positive reference control, $P<0.001$.

anti-ELAM-1 did not reduce the numbers of neutrophils recruited in response to instillation of glycogen into peritoneal cavities of rats (Fig. 1). It would appear that CL-3 may react at least in part with an ELAM-1 epitope that blocks interaction with the sial $\mathrm{Le}^{\mathrm{x}}$ moiety on the neutrophils $(21-23)$, whereas CL-37 reacts with a functionally irrelevant epitope on ELAM-1.

Anti-ELAM-1 related protection against immune complexinduced vascular injury. Acute vascular injury was induced in rat lung and skin after local injection of antibody (anti-BSA) and intravenous injection of BSA. As described above, four different doses of anti-BSA were used in lung and skin to achieve a range of injury. Endpoints for injury were leakage of ${ }^{125} \mathrm{I}$-albumin and extravasation into tissue of ${ }^{51} \mathrm{Cr}-\mathrm{RBC}$. Since acute injury in the lung commonly results in increased intravascular pressure which can be associated with increases in vascular surface area and possible recruitment of additional capillaries, the hemorrhage index was also used in most of the studies, since this represents an unequivocal parameter of vascular injury. Rats were treated either with three equal doses $(45 \mu \mathrm{g}$ each) of CL-3 anti-ELAM-1 (present as $F\left(a b^{\prime}\right)_{2}$ ) or with irrelevant $F\left(a b^{\prime}\right)_{2}$, each dose being injected intravenously at $2.5,3.0$, and $3.5 \mathrm{~h}$ after initiation of immune complex reactions. The results are shown in Figs. 2 and 3. In the lung, the anti-BSA concentrations of $0.75,1.50,2.50$, and $3.33 \mathrm{mg}$ produced progressive increases in vascular permeability proportional to the amount of anti-BSA injected into positive control animals (Fig. $2 \mathrm{~A}$ ). In animals treated with CL-3 anti-ELAM-1, there were significant reductions in vascular permeability (Fig. $2 A$ ). When the two groups were compared, using anti-BSA doses of $0.75,1.50,2.50$, and $3.33 \mathrm{mg}$, treatment with anti-ELAM-1 led to significant reductions in permeability values in lung of $94 \pm 8.5 \%, 96 \pm 9.0 \%, 52 \pm 10 \%$ and $13 \pm 5.1 \%$, respectively. Thus, treatment with anti-ELAM-1 resulted in marked protection that was statistically significant under all conditions except at the highest dose of anti-BSA. When hemorrhage was used as the indicator of injury in animals given $2.5 \mathrm{mg}$ anti-BSA intratracheally, there was a $94 \%$ reduction in injury in anti-ELAM-1

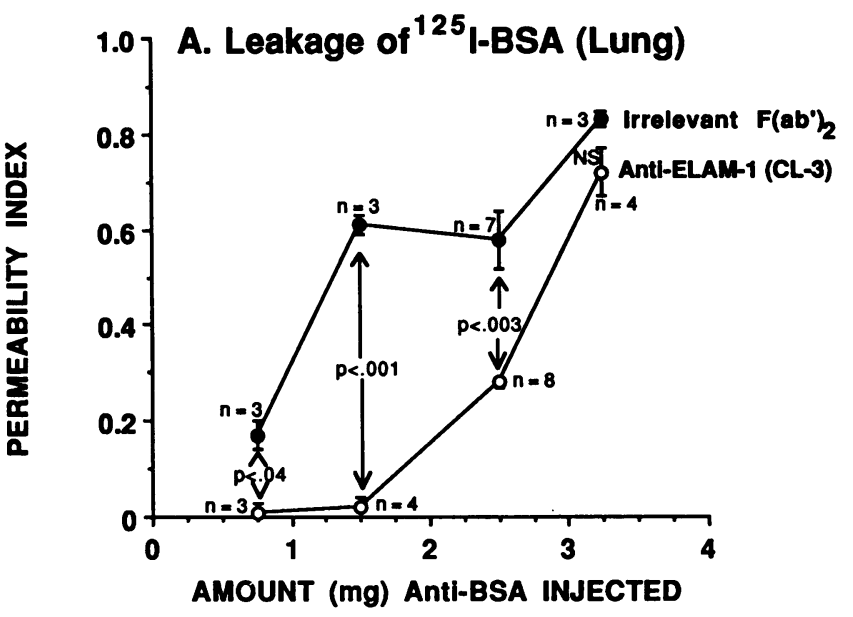

B. ${ }^{51}$ Cr-RBC (Lung)

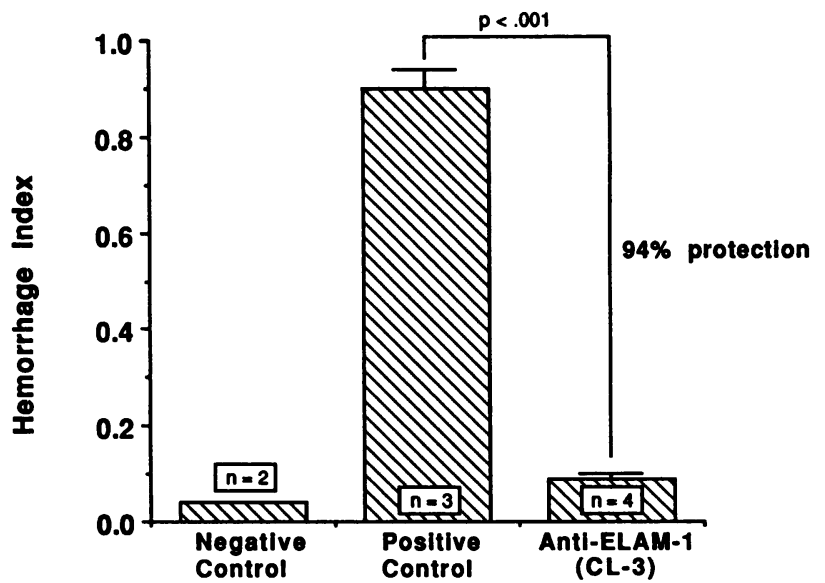

Figure 2. (A) Protective effects of $\mathrm{F}\left(\mathrm{ab}^{\prime}\right)_{2}$ anti-ELAM-1 (CL-3) in immune complex-induced vascular injury in lung. Four different doses of anti-BSA were used to achieve a range of injury. Injury was measured as increased vascular permeability as reflected by accumulation of ${ }^{125} \mathrm{I}$-albumin in lungs. All permeability values have been corrected for negative control values. The negative permeability mean value was $0.16 \pm 0.01$. Positive controls animals were injected with irrelevant $\mathrm{F}\left(\mathrm{ab}^{\prime}\right)_{2}$. All the data were first analyzed with a two-way ANOVA ( $P$ $<0.001$ ) and subsequent $t$ test revealed significant differences between positive controls and CL-3 treated groups at $.75 \mathrm{mg}$ anti-BSA $(P$ $<0.04), 1.5 \mathrm{mg}$ anti-BSA $(P<0.001)$, and $2.5 \mathrm{mg}$ anti-BSA $(P$ $<0.003)$. The difference between positive control and CL-3 treated groups at the highest dose of anti-BSA was not statistically significant. $(B)$ Protective effects of $F\left(a^{\prime}\right)_{2}$ anti-ELAM-1 (CL-3) on immune complex-induced vascular injury, as assessed by hemorrhage (extravasation of ${ }^{51} \mathrm{Cr}$-rat $\mathrm{RBC}$ from the blood). $2.5 \mathrm{mg}$ anti-BSA was instilled into the airway in all groups. Negative controls received no intravenous BSA. One-way ANOVA of the data revealed $P<0.001$.

Additional $t$ tests demonstrated significant differences between positive controls and negative controls $(P<0.001)$ and positive controls and CL-3 treated animals $(P<0.001)$. 
treated animals as compared to the positive controls that had been treated with irrelevant $\mathrm{F}\left(\mathrm{ab}^{\prime}\right)_{2}$ (Fig. 2 B).

Companion studies were done using the model of dermal vascular injury and employing a range of concentrations $(0.10$, $0.21,0.42$, and $0.84 \mathrm{mg}$ ) of anti-BSA per skin site. Again, rats were treated either with irrelevant $\mathrm{F}\left(\mathrm{ab}^{\prime}\right)_{2}$ (control animals) or with CL-3 anti-ELAM-1, as described above. The results in Fig. $3 A$ indicate that vascular injury as expressed by leakage of albumin was proportional to the dose of anti-BSA employed. In animals treated with anti-ELAM-1, there were significant reductions in the increased vascular permeability at all doses of anti-BSA employed. When comparisons between these two
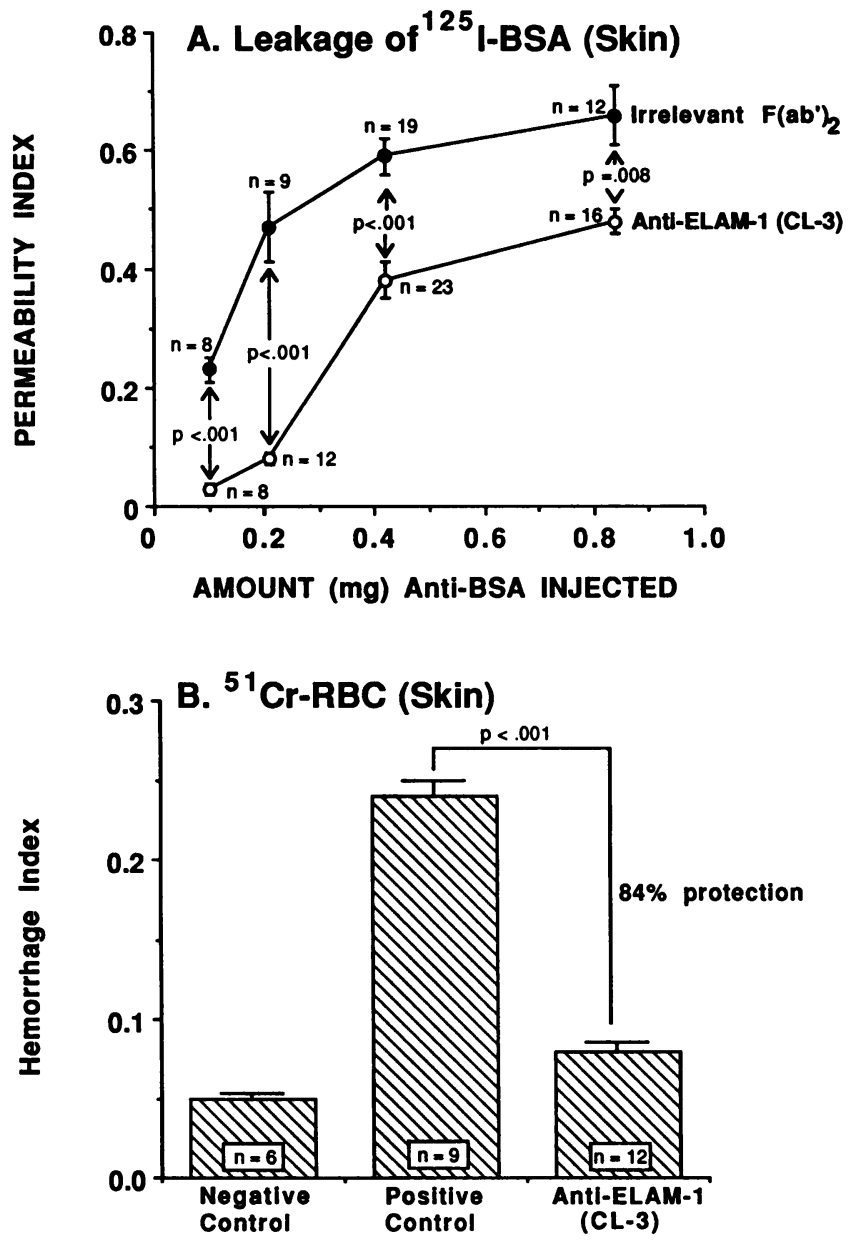

Figure 3. (A) Protective effects of $\mathrm{F}\left(\mathrm{ab}^{\prime}\right)_{2}$ anti-ELAM-1 (CL-3) in immune complex-induced dermal vascular injury. Four different doses of anti-BSA were used to achieve a range of injury. Injury was measured by increase vascular permeability as reflected by accumulation of ${ }^{125}$ I-BSA. All permeability values have been corrected for the mean negative control value $(0.11 \pm 0.01)$. Two-way ANOVA of all of the data revealed $P=0.027$. Subsequent $t$ tests revealed significant differences between positive controls and anti-ELAM treated animals at $0.1 \mathrm{mg}(P<0.001), 0.21 \mathrm{mg}(P<0.001), 0.42 \mathrm{mg}(P<0.001)$, and $0.84 \mathrm{mg}(P=0.008)$ anti-BSA. $(B)$ Protective effects of CL-3 against immune complex-induced dermal vasculitis as assessed by hemorrhage (extravasation of ${ }^{51} \mathrm{Cr}-\mathrm{RBC}$ ). One-way ANOVA of the data demonstrated $P<0.001$. Additional $t$ tests demonstrated significant differences between positive control and CL-3 treated groups ( $P$ $<0.001)$, positive and negative controls $(P<0.001)$, and negative controls and CL-3 treated animals $(P<0.001)$. groups were made at each concentration $(0.10,0.21,0.42,0.84$ $\mathrm{mg}$ ) of anti-BSA, the amounts of protection afforded by antiELAM- 1 were $87 \pm 5.9 \%, 83 \pm 8.9 \%, 36 \pm 4.8 \%$, and $27 \pm 5.0 \%$, respectively, all representing statistically significant protective effects. These results indicate that treatment with anti-ELAM1 provides protection against immune complex-induced injury in skin as well as lung. Comparison studies employing hemorrhage as the index of injury in skin revealed that, at the dose of $0.42 \mathrm{mg}$ anti-BSA, treatment with anti-ELAM-1 resulted in an $84 \%$ reduction in injury as contrasted to the use of irrelevant $\mathrm{F}\left(\mathrm{ab}^{\prime}\right)_{2}$ (Fig. $3 \mathrm{~B}$ ).

Reduction of neutrophil accumulation in lungs after immune complex deposition in anti-ELAM-1 treated animals. To assess if the protective effects of $\mathrm{F}\left(\mathrm{ab}^{\prime}\right)_{2}$ CL-3 anti-ELAM-1 could be related to attenuation of tissue accumulation of neutrophils after deposition of immune complexes, protocols similar to those described above were employed, using a range of concentrations of anti-BSA. In the lung, there were significant reductions $(>50 \%)$ in the amounts of tissue extractable MPO at all four concentrations of anti-BSA employed when animals had been treated with CL-37 anti-ELAM-1, as compared to treatment of rats with irrelevant $\mathrm{F}\left(\mathrm{ab}^{\prime}\right)_{2}$ (Fig. $4 A$ ). At each dose of antibody, the difference between the anti-ELAM-1 treated and untreated groups was statistically significant. The lack of a dose-response relationship between the amount of anti-BSA used and the amount of extractable MPO from lung probably reflects the relatively high doses of anti-BSA used as compared to results in the skin where much lower concentrations of antiBSA were used (see below).

When skin sites injected with $0.10-0.84 \mathrm{mg}$ anti-BSA were also evaluated for extractable MPO content, a proportionality between dose of anti-BSA and skin content of MPO was noted, with a plateau occurring at the two highest doses of anti-BSA (Fig. 4 B). In animals treated with CL-3 anti-ELAM-1 (as compared to animals treated with irrelevant $\left.F\left(a b^{\prime}\right)_{2}\right)$, there was a statistically significant reduction in the amount of MPO at each dose of anti-BSA used (Fig. $4 \mathrm{~B}$ ). Thus, the protective effects of CL-3 anti-ELAM-1 in immune complex-induced injury of lung and skin are associated with reductions in amounts of neutrophils accumulating in tissues bearing deposits of immune complexes.

To use an independent approach to assess the role of antiELAM-1 on lung accumulation of neutrophils, three groups of rats ( $n=4$ each) were used: negative controls (receiving $2.5 \mathrm{mg}$ anti-BSA intratracheally in the absence of intravenously injected BSA); positive controls (receiving $2.5 \mathrm{mg}$ anti-BSA intratracheally and $10 \mathrm{mg}$ BSA intravenously) and $135 \mu \mathrm{g}$ irrelevant $\mathrm{F}\left(\mathrm{ab}^{\prime}\right)_{2}$ in three equally divided doses at $2.5,3.0$, and $3.5 \mathrm{~h}$; and positive controls similarly treated but injected with a total of $135 \mu \mathrm{g} \mathrm{CL-3}$ anti-ELAM-1. At $4.0 \mathrm{~h}$ bronchoalveolar lavage was carried out and neutrophil content in the fluids assessed by microcytometry. The results of these experiments are shown in Fig. 5. In the negative controls, the neutrophil content was $<2$ $\times 10^{5}$ /animal. The positive controls yielded mean neutrophil counts of $104.5 \pm 3.60 \times 10^{6}$, while in positive control animals also treated with anti-ELAM-1 the neutrophil counts were $55.5 \pm 0.75 \times 10^{6}$, indicating a $47 \%$ reduction $(P=.017)$. Accordingly, these data confirm the results obtained with MPO extraction and indicate that treatment with anti-ELAM-1 reduces tissue accumulation of neutrophils. As will be described below, these findings are consistent with morphological evaluation concerning the protective effects of anti-ELAM-1. 


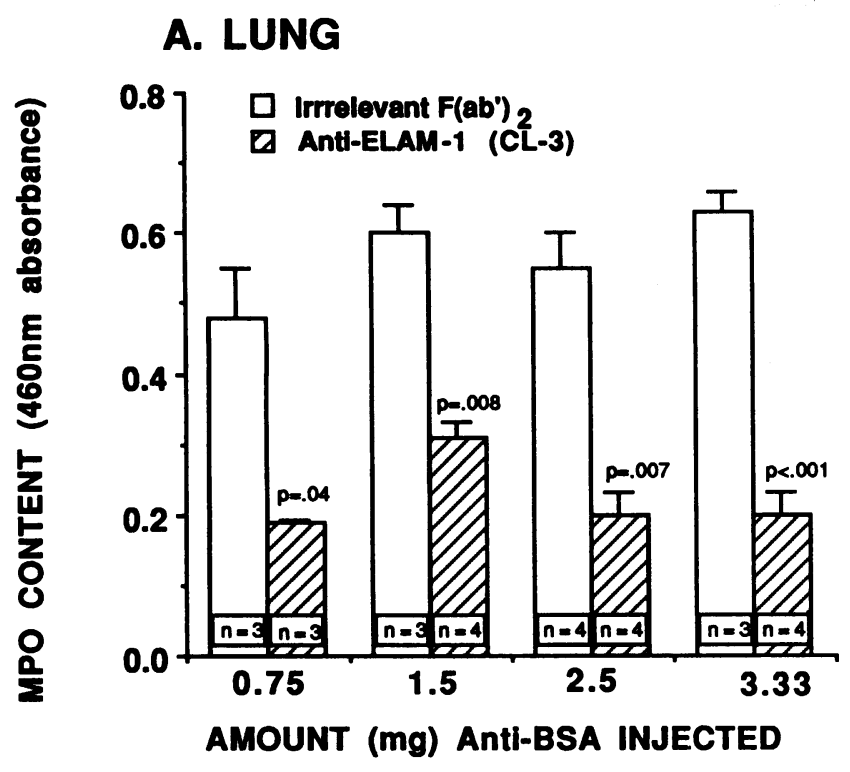

\section{B. SKIN}

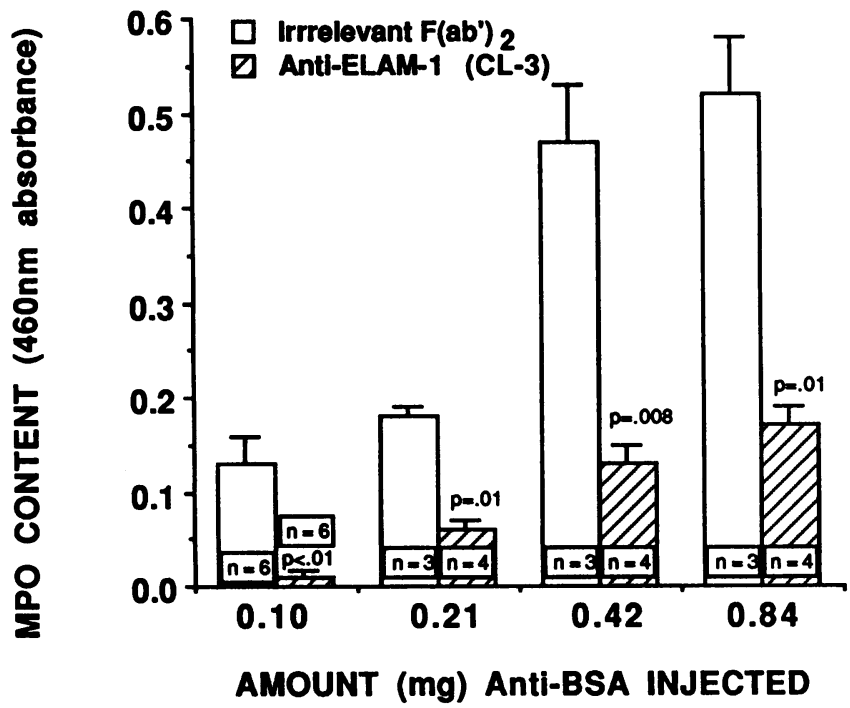

Figure 4. Extraction of myeloperoxidase (MPO) from lung $(A)$ and skin $(B)$ tissues of animals treated with irrelevant $\mathrm{F}\left(\mathrm{ab}^{\prime}\right)_{2}$ (open bars) or anti-ELAM-1 (CL-3) (striped bars) as described in the text. Lung and skin tissues were extracted and MPO content in soluble extracts was assessed enzymatically by spectrophometric analysis, as described in Methods. Doses of anti-BSA were similar to those used for the protocols in Figs. $2 A$ and $3 A$. Two-way ANOVA of the lung data $(A)$ revealed $P$, NS. However, additional $t$ tests revealed significant differences between pairs of positive controls and CL-3 treated animals at each dose of anti-BSA ( $P$ values in figure). Two-way ANOVA of the skin MPO data $(B)$ revealed $P<0.001$. Additional $t$ tests reveal significant difference between positive control and CL-3 treated groups at doses of $0.1 \mathrm{mg}(P<0.01), 0.21 \mathrm{mg}(P=0.01), 0.42 \mathrm{mg}$ $(P=0.008)$, and $0.84 \mathrm{mg}(P=0.01)$ anti-BSA.

Immunohistochemical analysis of pulmonary artery endothelial cells and pulmonary vasculature for ELAM-1. Monolayers of RPAEC were exposed to either $50 \mathrm{ng} / \mathrm{ml}$ recombinant human TNF $\alpha$ or HBSS for $4 \mathrm{~h}$, washed, and then incubated (45 min) with CL-3 anti-ELAM-1 $\left(\mathrm{F}\left(\mathrm{ab}^{\prime}\right)_{2}\right)(1.0 \mathrm{ng} / \mathrm{ml})$, followed by immunoperoxidase staining, according to procedures described above. RPAEC that had been exposed to TNF $\alpha$ showed a high degree of reactivity (Fig. $6 \mathrm{~A}$ ) whereas cells not exposed to TNF $\alpha$ showed little or no evidence of staining (Fig. $6 \mathrm{~B}$ ). These data indicate that CL-3 anti-ELAM-1 detects a TNF $\alpha$ inducible product in RPAEC. The time course of induction of ELAM- 1 reactivity in TNF $\alpha$-treated RPAEC, as assessed by immunoperoxidase reactivity, revealed little or no staining during the first $2 \mathrm{~h}$, but intense staining at 3 and $4 \mathrm{~h}$ (data not shown). When CL-37 anti-ELAM-1 was used, the results in staining of rat pulmonary artery endothelial cells were similar to the data obtained with CL-3 (data not shown). Additional studies were designed to determine if, by immunohistochemical analysis of lung tissue, there was observable upregulation in the appearance of ELAM-1-reactivity during the time course of immune complex-induced lung injury. Intraalveolar immune complex deposition was produced in the usual manner, using $2.50 \mathrm{mg}$ anti-BSA. At times $0,1,3$ and $4 \mathrm{~h}$ after injection of BSA and anti-BSA, lungs were harvested, inflated with OCT compound, and snap frozen. Frozen sections of lung were then obtained and the tissue sections reacted with reagents used for the detection of material reactive with CL-3 anti-ELAM-1, as described above. The results of these studies are shown in Fig. $6, c-f$. At time 0 (immediately after intratracheal instillation of anti-BSA and intravenous injection of $10 \mathrm{mg} \mathrm{BSA}$ ), no staining of the pulmonary vasculature could be discerned (Fig. $6 c$ ). At 1 $h$ there was barely detectable staining for ELAM-1 in the walls of venules (frame $d$ ). By $3 \mathrm{~h}$ there was more regular staining of the venules and beginning evidence for staining of structures within the pulmonary septae (frame $e$ ). Staining of pulmonary arterioles for ELAM-1 did not occur (data not shown). By $4 \mathrm{~h}$ there was heavy staining for ELAM-1 in venular walls as well as

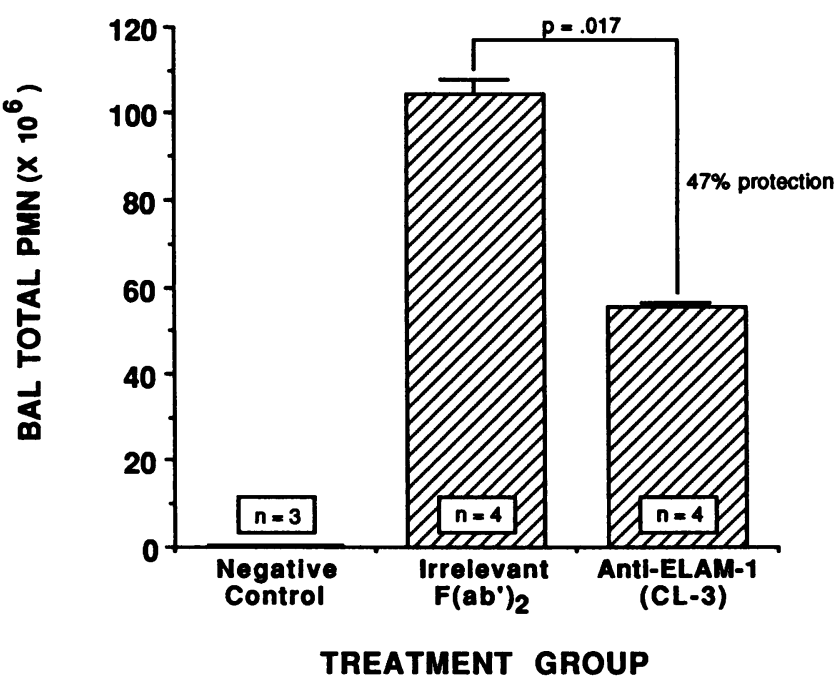

Figure 5. Retrieval of neutrophils from lung by bronchoalveolar lavage after immune complex deposition and treatment of rats with irrelevant $F\left(a b^{\prime}\right)_{2}$ or anti-ELAM-1 $F\left(a b^{\prime}\right)_{2}$. The negative controls, which received $2.5 \mathrm{mg}$ anti-BSA intratracheally but no BSA intravenously, had a mean yield of neutrophils of $<2 \times 10^{5}$. The positive controls had a mean yield of $104 \pm 3.6 \times 10^{5}$ while positive controls treated with anti-ELAM-1 had a yield that was reduced by $47 \%$. One-way ANOVA for all the data yielded $P<0.001$. Additional $t$ tests revealed significant difference between positive controls and negative controls $P<0.006$, positive controls and CL-3 treated rats $(P$ $=0.017$ ), and negative controls and CL-3 treated animals $P<0.001$. 

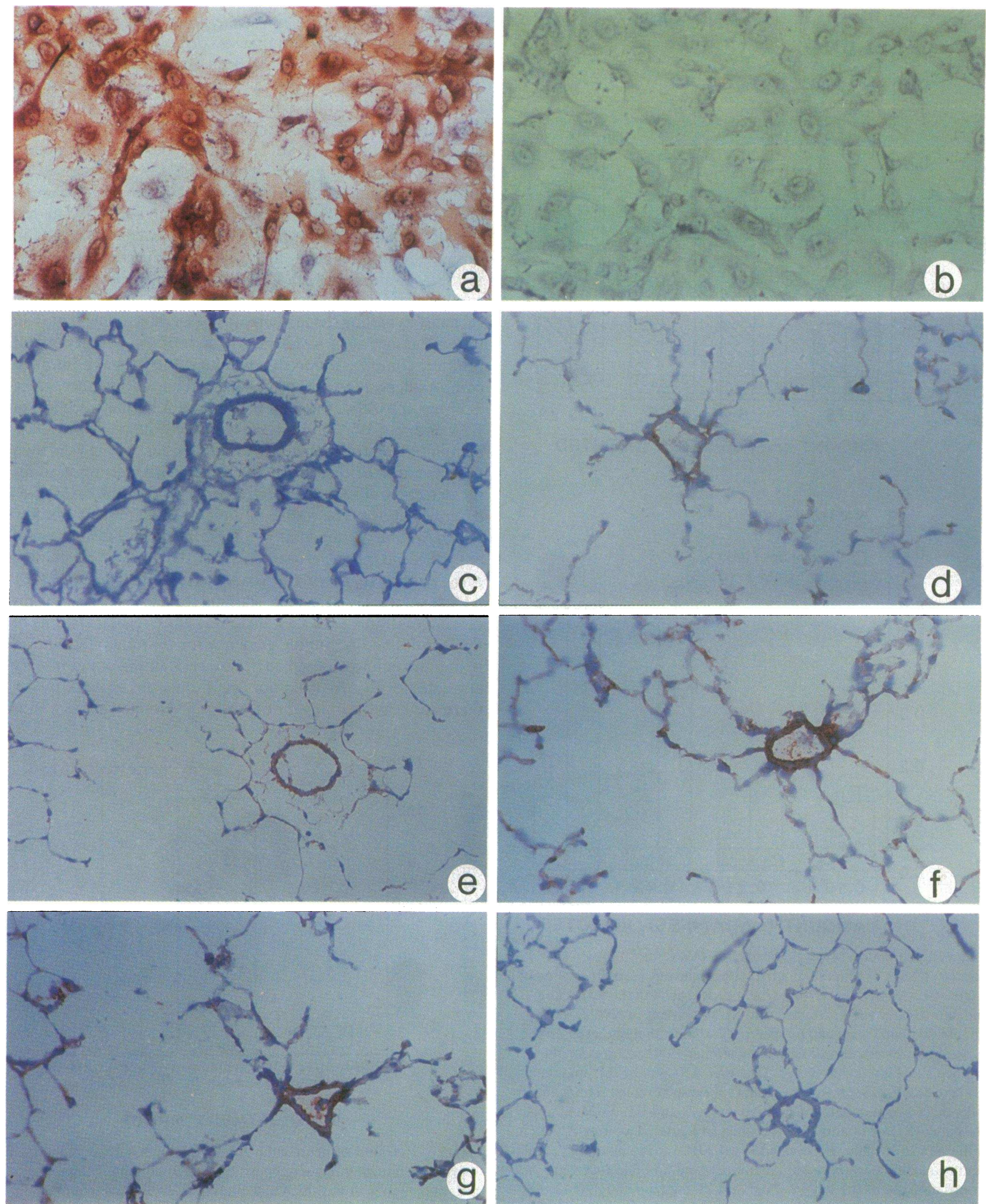

Figure 6. Immunoperoxidase analyses of cells and frozen sections of lung tissue. Rat pulmonary artery endothelial cells (RPAEC) were exposed in vitro to TNF $\alpha(a)$ or to HBSS $(b)$ for $4 \mathrm{~h}$, washed, and then stained with CL-3 anti-ELAM-1. Frozen sections of lungs from animals undergoing immune complex deposition were stained for presence of ELAM-1 at $0,1,3$, and $4 \mathrm{~h}$ after deposition of immune complexes (c-f, respectively). ELAM-1 reactivity is absent at time $0(c)$, barely detectable at $1 \mathrm{~h}(d)$, but strongly expressed at 3 and $4 \mathrm{~h}(e, f)$. Finally, lung sections $4 \mathrm{~h}$ after deposition of immune complexes were reacted with CL-3 anti-ELAM-1 that had been absorbed with HBSS-treated human umbilical vein endothelial cells (HUVEC) $(g)$ or with TNF $\alpha$-treated HUVEC $(h)$ and the tissues then reacted with the peroxidase indicator. (Frames $a, b, \times 400$; frames $c-h, \times 150$ ). 
clear evidence of staining within alveolar septal walls (frame $f$ ). The intense staining of alveolar septal walls is consistent with reactivity of capillary endothelial cells. The frozen section technique did not permit a higher degree of morphological resolution. Attempts to date to obtain staining of lung tissue that has been fixed in paraformaldehyde or phosphate-buffered formaldehyde have not been successful (data not shown). The staining of lung sections obtained $4 \mathrm{~h}$ after immune complex deposition was unaffected if the anti-ELAM-1 preparation was reacted with nonstimulated HUVEC (frame $g$ ), but the staining of lung tissue was abolished if anti-ELAM-1 was first absorbed with HUVEC monolayers that had been preincubated for $4 \mathrm{~h}$ with TNF $\alpha$ (frame $h$ ). These findings indicate a remarkably increased reactivity of the rat lung vasculature with anti-ELAM-1 antibody in a time course that requires several hours after initiation of immune complex deposition before maximal staining with CL-3 occurs. These features are consistent with the known in vitro time course for upregulation of ELAM-1 in HUVEC (9) and suggest that this upregulation in the rat pulmonary vasculature is required for the recruitment of neutrophils into sites of immune complex deposits. The time course in expression of ELAM-1 in rat lung is remarkably consistent with a similar pattern of upregulation of ELAM-1 in rat pulmonary artery endothelial cells incubated in vitro with TNF $\alpha$ (see above).

When frozen sections of liver, kidney, and spleen were obtained from rats $4 \mathrm{~h}$ after immune complex deposition in lungs, immunoperoxidase staining with CL-3 anti-ELAM-1 failed to demonstrate expression of ELAM-1 in any of these extrapulmonary tissues (data not shown).

Morphological correlates of protective effects of anti-ELAM1. Light microscopy was used to evaluate changes $4 \mathrm{~h}$ after deposition of immune complexes in skin and lung, using 0.42 and $2.50 \mathrm{mg}$ anti-BSA, respectively. The data in Figs. 4 and 5 were predictive of diminished recruitment of neutrophils. The histopathologic findings are demonstrated in Fig. 7. The intradermal sites in animals treated with irrelevant $F\left(a^{\prime}\right)_{2}$ showed the usual dense infiltration of venular walls with neutrophils as well as the presence of neutrophils and $\mathrm{RBC}$ in the edematous interstitial connective tissue (frame $a$ ). In striking contrast, skin sites from animals treated systemically with CL-3 anti-ELAM1 demonstrated very few neutrophils in any location and there was little or no evidence of edema or hemorrhage in pervascular areas (frame $b$ ). In lungs from positive reference control animals, there was extensive intraalveolar hemorrhage, fibrin deposition, and accumulation of neutrophils (frame $c$ ), in contrast to CL-3 anti-ELAM-1 treated rats in which the alveolar compartment contained very few RBC, neutrophils, and fibrin deposits (frame $d$ ). The precise geography of neutrophil localization in these lungs, involving endothelial cell-adherent neutrophils versus transmigrated neutrophils, is not currently known. A complete analysis to define the location these neutrophils in the pulmonary vasculature is currently underway. Based on tissue extraction of MPO and morphological analysis, CL-3 ELAM-1 is, therefore, highly protective against immune complex-induced injury, its protective effects being correlated with greatly diminished influx of neutrophils.

Absence of suppressive effects of anti-ELAM-1 on neutrophil function. The protective effects of CL-3 anti-ELAM-1 could conceivably be due to an unexpected reactivity of the antibody with neutrophils. Two different approaches were used to address this question. First, we observed the effects of anti-
ELAM-1 infusion (three separate intravenous infusions of $\mathbf{4 5}$ $\mu \mathrm{g}$ each, as described above) on blood neutrophil counts in normal rats and in those undergoing immune complex deposition in lung. For the 90 -min interval after the third infusion of anti-ELAM-1, there was no decrease in the total blood leukocyte count or in the neutrophil count (data not shown). Assuming no extravascular equilibration or renal excretion of this molecule (both assumptions being exceedingly unlikely), the plasma concentration of anti-ELAM-1 would be $\sim \mu \mathrm{g} / \mathrm{ml}$. Accordingly, for some of the in vitro studies, concentrations of $7 \mu \mathrm{g} / \mathrm{ml}$ or greater were used (see below).

Second, we assessed the extent to which CL-3 anti-ELAM-1 would interfere, in vitro, with either neutrophil $\mathrm{O}_{2}^{-}$production or chemotactic migration in response to the chemotactic peptide, FMLP. For assessment of $\mathrm{O}_{2}^{-}$production, cytochalasin B was added to enhance the limited $\mathrm{O}_{2}^{-}$response of rat cells to 100 nM FMLP (18). Anti-ELAM-1 at a dose of $25 \mu \mathrm{g} / \mathrm{ml}$ did not affect the $\mathrm{O}_{2}^{-}$responses of neutrophils and at $7 \mu \mathrm{g} / \mathrm{ml}$ did not alter the chemotactic motility of neutrophils. In the absence of anti-ELAM-1, FMLP (100 nM) stimulation caused $2 \times 10^{6}$ rat neutrophils to produce $8.9 \pm 0.4 \mathrm{nmol} \mathrm{O}_{2}^{-} / 20 \mathrm{~min}$ while, when anti-ELAM-1 was present, the value was $8.6 \pm 1.1 \mathrm{nmol} \mathrm{O}_{2}^{-} / 20$ min. $(P, N S)$. Likewise, using the leading front method of chemotaxis measurement, in the absence of anti-ELAM-1 the negative (no FMLP) and positive $\left(10^{-8} \mathrm{nM}\right.$ FMLP) values were $26.7 \pm 6.4$ and $125 \pm 9.6 \mu \mathrm{m}$, respectively. In the presence of anti-ELAM-1, the negative and positive control values were $30 \pm 5.8$ and $123 \pm 4.4 \mathrm{~nm}$, respectively. Thus, using either functional parameter of neutrophil function $\left(\mathrm{O}_{2}^{-}\right.$production or chemotactic migration), there was no evidence that CL-3 antiELAM-1 interferes with responsiveness of rat neutrophils. Under similar conditions, CL-3 also failed to affect chemotactic migration or $\mathrm{O}_{2}^{-}$responses of FMLP-stimulated human neutrophils (data not shown).

Inability of CL-37 anti-ELAM-1 to protect against immune complex-induced lung injury. To control for the effects of CL-3 anti-ELAM-1, another $F\left(a b^{\prime}\right)_{2}$ anti-ELAM-1, CL-37, was used. As indicated above, CL-37 anti-ELAM-1 neither blocked the cytotoxic effects on RPAEC of phorbol ester activated neutrophils (Table I), nor did it block recruitment of neutrophils into peritoneal cavities injected with glycogen (Fig. 1). Based on immunohistochemical analysis, CL-37 anti-ELAM-1 was at least as reactive as CL-3 in the staining of RPAEC that had been exposed for $4 \mathrm{~h}$ to TNF $\alpha$ (data not shown). CL-37 antibody was also highly reactive with sections from lungs $4 \mathrm{~h}$ after immune complex deposition (data not shown), similar to the findings in Fig. 6 ( $e$ and $f$ ) where CL-3 was used. However, when the same protocol that had been used with CL-3 antiELAM-1 (Fig. 2) was used for assessment of effects of CL-37 anti-ELAM-1 on immune complex-induced lung injury after airway instillation of $2.50 \mathrm{mg}$ anti-BSA, CL-37 was without any protective effects (Fig. 8). Thus, while both antibodies are reactive with TNF $\alpha$-treated RPAEC and with lung sections from animals developing immune complex-induced injury, only one (CL-3) of the two antibodies to ELAM-1 was protective in vivo against immune complex induced lung injury.

\section{Discussion}

The significantly protective effects of CL-3 anti-ELAM-1 in IgG immune complex-induced vascular injury are related to 

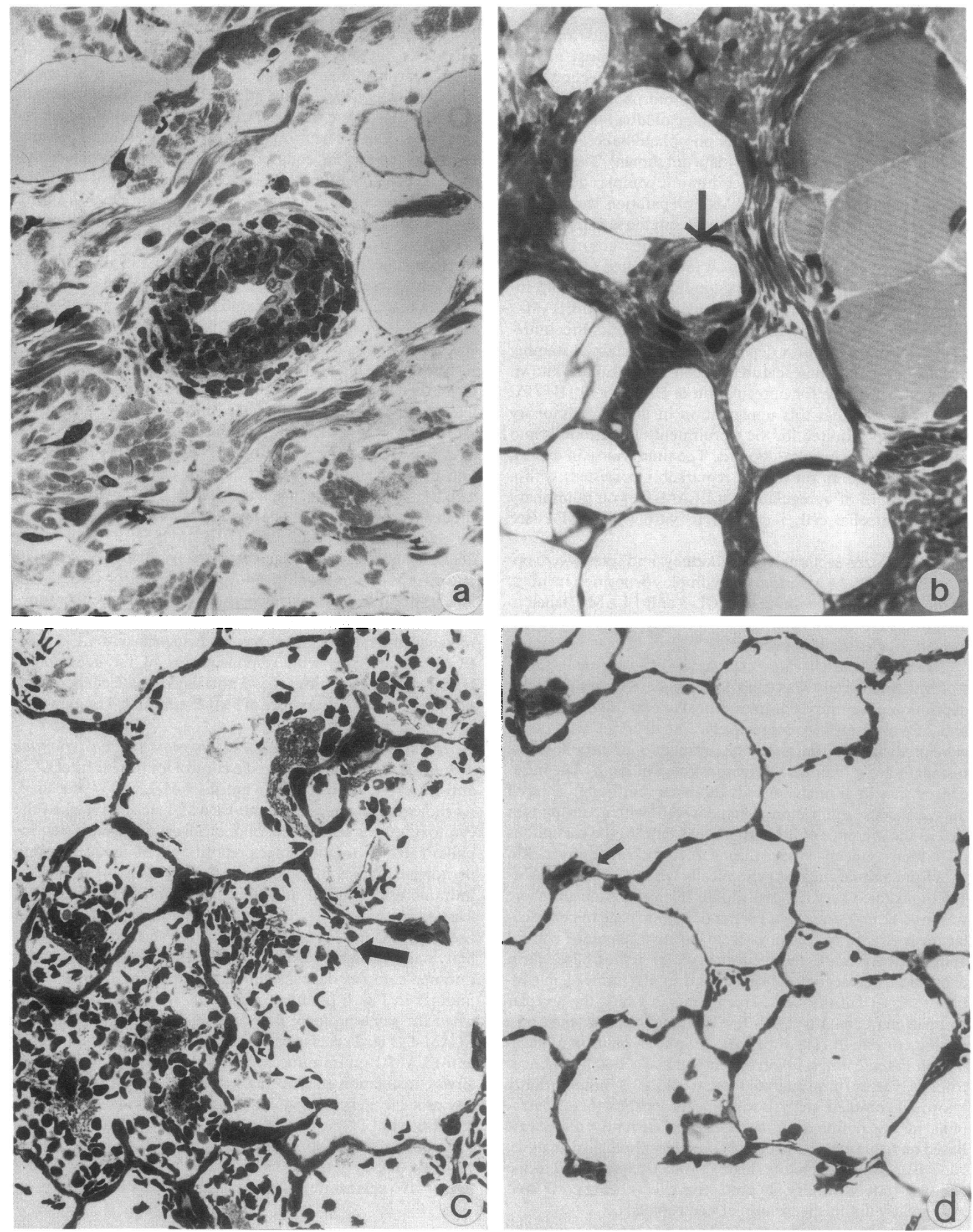

Figure 7. Morphological features of immune complex-induced reactions in skin and lung. Skin sites $(a, b)$ and lung sites $(c, d)$ were obtained from animals treated with irrelevant $\mathrm{F}\left(\mathrm{ab}^{\prime}\right)_{2}(a, c)$ or with anti-ELAM-1 $\mathrm{F}\left(\mathrm{ab}^{\prime}\right)_{2}(b, d)$. In frame $b$, arrow indicates an intradermal venule that has no intramural neutrophils. In frame $c$, arrow indicates intraalveolar deposits of fibrin, in addition to the presence of neutrophils and RBC. In frame $d$, arrow indicates presence of occasional interstitial neutrophils (hematoxylin and eosin, $\times 200$ ). 


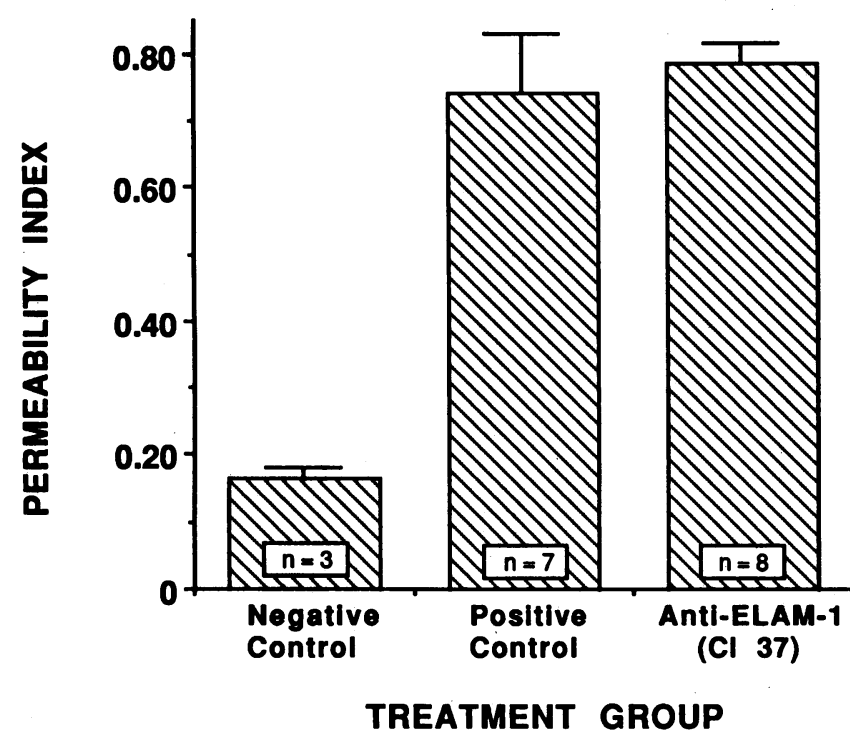

Figure 8. Inability of CL-37 anti-ELAM-1 to protect against immune complex-induced lung injury after instillation of $2.5 \mathrm{mg}$ anti-BSA into rat lungs. Injury was measured by leakage of ${ }^{125} \mathrm{I}$-albumin into lung parenchyma. The negative and positive controls were treated with irrelevant $\mathrm{F}\left(\mathrm{ab}^{\prime}\right)_{2}$. One-way ANOVA of the data revealed $P$ $<0.001$. Additional $t$ tests demonstrated significant differences between negative controls and the two groups with intrapulmonary deposition of immune complexes $(P<0.001)$. No significant difference was found between the positive control and CL-3 treated groups.

interference with the influx into tissues of neutrophils (Figs. 4, 5, and 7), suggesting that expression of ELAM-1 on endothelial cells is crucial for the migration of neutrophils into tissue sites containing immune complexes. RPAEC can be induced in vitro with TNF $\alpha$ to express reactivity with CL-3 (or CL-37) antiELAM-1 (Fig. 6). Additionally, the pulmonary vasculature of animals developing immune complex alveolitis over $4 \mathrm{~h}$ expresses increasing reactivity with these anti-ELAM-1 (CL-3 and CL-37) preparations (Fig. 6). These findings are consistent with what is currently known in vitro about upregulation of ELAM-1 in stimulated endothelial cells. Also consistent is the loss of staining for ELAM-1 in the pulmonary vasculature (from immune complex-injured animals) if the CL-3 antibody preparation had first been absorbed with TNF $\alpha$-treated HUVEC (Fig. $6 h$ ). The inability of CL-3 to react by flow cytometric analysis with rat neutrophils, monocytes or platelets suggests that this MAb does not react with other members of the LEC-CAM family.

It is important to underscore the close temporal relationship between in vitro TNF $\alpha$ upregulation of ELAM-1 in RPAEC, the upregulation of ELAM-1 in lung after intrapulmonary deposition of immune complexes (both described above), and the accumulation of neutrophils after deposition of IgG immune complexes (as described in a recent study from our laboratories) (9). With respect to ELAM-1 expression in vitro or in vivo, it is first detectable $\sim 2.5 \mathrm{~h}$ after exposure of RPAEC to TNF $\alpha$ or following intrapulmonary deposition of immune complexes, demonstrating an increasing appearance of ELAM-1 over time, with a peak between 3.5 and $4.0 \mathrm{~h}$. This is precisely the time course for neutrophil accumulation in rat lungs after immune complex deposition (24). These findings would support the concept suggested in this paper that ELAM-
1 expression plays a key role in intrapulmonary accumulation of neutrophils following deposition of immune complexes.

The control for ELAM-1-reactive CL-3 was CL-37, which represents another monoclonal antibody developed towards human ELAM-1, as identified by its reactivity with COS cells that had been transfected with the cDNA for human ELAM-1. In contrast to CL-3, CL-37 appears to recognize an epitope not involved in adhesive interactions of endothelial cells with neutrophils. CL-37 only slightly inhibited the adhesion of human neutrophils to IL-1 stimulated HUVEC (Smith, C. W., unpublished) or TNF $\alpha$-stimulated RPAEC. CL-37 also offered no protection against killing of TNF $\alpha$-stimulated RPAEC by PMA-stimulated neutrophils. CL-37 anti-ELAM-1 was also found to react with TNF $\alpha$-treated RPAEC and with tissue sections from rat lungs $4 \mathrm{~h}$ after deposition of immune complexes (Table I). Consistent with this observation, CL-37 neither protected against IgG immune complex-induced lung injury (Fig. 8) nor did it interfere with recruitment of neutrophils into glycogen-injected peritoneal cavities (Fig. 1). These data suggest that, while CL-37 is reactive with ELAM-1, reactivity is to an epitope not involved in adhesive interactions between rat neutrophils and pulmonary vascular endothelial cells.

The data in this paper may be relevant to a recent observation in rats that also underwent IgG immune complex-induced alveolitis. Bronchoalveolar fluid from these animals was found to contain high levels of TNF $\alpha$. When animals were treated with antibody to TNF $\alpha$, such that no TNF $\alpha$ biological activity could be detected in bronchoalveolar fluids, the lungs were dramatically protected from injury. This protection was related to a greatly diminished influx of neutrophils (16). Such observations, together with the data in this paper, suggest that immune complex deposition triggers in lung the release of TNF $\alpha$, which then causes upregulation of ELAM- 1 in pulmonary venules and septal capillaries. These events would then appear to facilitate the adherence of neutrophils to endothelial cells containing upregulated amounts of ELAM-1 on their cell surfaces, after which neutrophil emigration presumably occurs in response to C5a that has been generated within alveoli. In recent studies, we have demonstrated that, if rats undergoing intrapulmonary deposition of IgG immune complexes are also treated with antibody to TNF $\alpha$, this results in a lack of upregulation of ELAM-1 in the pulmonary microvasculature, a finding consistent with the lack of influx of neutrophils (Mulligan, M. S., and P. A. Ward, submitted for publication).

The complexities in defining the in vivo role of adhesionpromoting molecules are apparent in this report. Although both CL-37 and CL-3 are highly reactive immunohistochemically with cytokine-stimulated RPAEC, only the latter blocks in vitro killing of RPAEC by stimulated neutrophils and only CL-3 has in vivo protective effects. Had the in vivo experiments been carried out exclusively with CL-37, conclusions might have been drawn that ELAM-1 plays no role in either neutrophil recruitment or in the ultimate expression of tissue injury, and that the expression of ELAM-1 in tissues is an interesting but irrelevant curiosity. Accordingly, negative results in biological systems using monoclonal antibodies to adhesion molecules must be interpreted with caution. Simple technical problems such as the critical timing for infusion of the antiELAM-1 antibodies $\left(\mathrm{F}\left(\mathrm{ab}^{\prime}\right)_{2}\right)$ also need to be taken into account in the event of a negative result. Indeed, in pilot studies in which CL-3 $\mathrm{F}\left(\mathrm{ab}^{\prime}\right)_{2}$ anti-ELAM-1 was infused shortly after BSA injection, little protection was found (data not shown). 
The rapid clearance of this protein, together with the knowledge that the most intense intrapulmonary expression of ELAM-1 occurs 3 and $4 \mathrm{~h}$ after deposition of immune complexes (Fig. 6), explains the negative result and the critical timing for infusion of anti-ELAM-1. Finally, although intact IgG $_{1}$ anti-ELAM-1 antibodies would overcome the problem of in vivo rapid clearance, we have found them to be unreliable. In fact, using intact $\operatorname{IgG}_{1}$ CL-3 anti-ELAM-1, in vitro injury to RPAEC by phorbol ester stimulated human neutrophils actually accentuated, and immune complex injury to lung (of the type described in this report) was also accentuated (data not shown), presumably due to engagement of $F c \gamma R$ receptors of neutrophils and/or (in the case of in vivo studies of developing immune complex-induced lung injury) complement fixation on the surface of endothelial cells, leading to direct endothelial cell injury by the membrane attack complex, C5b-9.

Although there are abundant data indicative of the role of ELAM-1 in adhesive interactions between lymphocytes and neutrophils and cytokine-stimulated endothelial cells in vitro $(7,11,25-29)$, its role in vivo previously had not been assessed. ELAM-1 is expressed on venular endothelial cells in humans at sites of acute (29) and chronic (28) inflammation, and in primates at skin sites following cytokine injection (30). While it is not clear what role ELAM-1 may play in chronic inflammation, its presence at skin sites where the inflammatory infiltrate consists predominantly of mononuclear leukocytes supports the observations in vitro that ELAM-1 may also serve as an adhesion molecule for lymphocytes $(27,28,31)$. Our results provide the first evidence that ELAM-1 participates in some acute inflammatory reactions and plays a pivotal role in neutrophil extravasation and injury in immune complex-induced lung inflammation. This is of particular interest in light of recent evidence that there are CD18-independent mechanisms of neutrophil immigration into the lungs of rabbits (5), humans (2), and rats (Mulligan, M.S., et al., submitted for publication).

\section{Acknowledgments}

We acknowledge with thanks the illustrative support of Robin G. Kunkel and the secretarial support of Kimberly D. Lowe.

Supported in part by National Institutes of Health grants HL40526, HL-31963, GM-29507, and GM-28737.

\section{References}

1. Anderson, D. C., and T. A. Springer. 1987. Leukocyte adhesion deficiency: an inherited defect in the Mac-1, LFA-1 and p150,95 glycoproteins. Annu. Rev. Med. 38:175-194.

2. Carlos, T. M., and J. M. Harlan. 1990. Membrane proteins involved in phagocyte adherence to endothelium. Immunol. Rev. 114:45-28.

3. Barton, R. W., R. Rothlein, J. Ksiazek, and C. Kennedy. 1989. The effect of anti-intercellular adhesion molecule-1 on phorbol-ester-induced rabbit lung inflammation. J. Immunol. 143:1278-1282.

4. Seewaldt-Becker, E., R. Rothlein, and J. W. Dammgen. 1989. CDw18 dependent adhesion of leukocytes to endothelium and its relevance for cardiac reperfusion. In Leukocyte Adhesion Molecules: Structure, Function, and Regulation. T. A. Springer, D. C. Anderson, A. S. Rosenthal, and R. Rothlein, editors. Springer-Verlag, New York. 138-148.

5. Doerschuk, C. M., R. K. Winn, H. O. Coxson, and J. M. Harlan. 1990. CD18-dependent and independent mechanisms of neutrophil emigration in the pulmonary and systemic microcirculation of rabbits. J. Immunol. 144:23272333.

6. Stoolman, L. M. 1989. Adhesion molecules controlling lymphocyte migration. Cell. 56:907-910.

7. Bevilacqua, M. P., S. Stengelin, Jr., M. A. Gimbrone, and B. Seed. 1989. Endothelial leukocyte adhesion molecule 1: an inducible receptor for neutrophils related to complement regulatory proteins and lectins. Science (Wash. DC). 243:1160-1165.
8. Geng, J., M. P. Bevilacqua, K. L. Moore, T. M. McIntyre, S. M. Prescott, J. M. Kim, G. A. Bliss, G. A. Zimmerman, and R. P. McEver. 1990. Rapid neutrophils adhesion to activated endothelium mediated by GMP-140. Nature (Lond.). 343:757-760.

9. Hallmann, R., M. A. Jutila, C. W. Smith, D. C. Anderson, T. K. Kishimoto, and E. C. Butcher. 1991. The peripheral lymph node homing receptor, LECAM1 , is involved in CD-18-independent adhesion of human neutrophils to endothelium. Biochem. Biophys. Res. Commun. 174:236-243.

10. Smith, C. W., T. K. Kishimoto, O. Abbassi, B. Hughes, R. Rothlein, L. V. McIntire, E. Butcher, and D. C. Anderson. 1991. Chemotactic factors regulate Lectin Adhesion Molecule 1 (LECAM-1)-dependent neutrophil adhesion to cytokine-stimulated endothelial cells in vitro. J. Clin. Invest. 87:609-618.

11. Luscinskas, F. W., A. F. Brock, M. A. Arnaout, and M. A. Gimbrone, Jr. 1989. Endothelial-leukocyte adhesion molecule-1-dependent and leukocyte (CD11/CD18)-dependent mechanisms contribute to polymorphonuclear leukocyte adhesion to cytokine-activated human vascular endothelium. J. Immunol. 142:2257-2263.

12. Jutila, M. A., L. Rott, E. L. Berg, and E. C. Butcher. 1989. Function and regulation of the neutrophil MEL-14 antigen in vivo: comparison with LFA-1 and MAC-1. J. Immunol. 143:3318-3324.

13. Smith, C. W., S. D. Marlin, R. Rothlein, C. Toman, and D. C. Anderson. 1989. Cooperative interactions of LFA-1 and Mac-1 with intercellular adhesion molecule-1 in facilitating adherence and transendothelial migration of human neutrophils in vitro. J. Clin. Invest. 83:2008-2017.

14. Bevilacqua, M. P., S. Stengelin, M. A. Gimbrone, Jr., and B. Seed. 1989. Endothelial leukocyte adhesion molecule-1: an inducible receptor for neutrophils related to complement regulatory proteins and lectins. Science (Wash. DC). 243:1160-1165.

15. Johnson, K. J., and P. A. Ward. 1981. Role of oxygen metabolites in immune complex injury of lung. J. Immunol. 126:2365-2369.

16. Warren, J. S., K. R. Yabroff, D. G. Remick, S. L. Kunkel, S. W. Chensue, R. G. Kunkel, K. J. Johnson, and P. A. Ward. 1989. Tumor necrosis factor participates in the pathogenesis of acute immune complex alveolitis in the rat. $J$. Clin. Invest. 84:1873-1882.

17. Varani, J., S. E. G. Fligiel, G. O. Till, R. G. Kunkel, U. S. Ryan, and P. A. Ward. 1985. Pulmonary endothelial cell killing by human neutrophils: possible involvement of hydroxyl radical. Lab. Invest. 53:656-663.

18. Ward, P. A., T. W. Cunningham, and K. J. Johnson. 1989. Signal transduction events in stimulated rat neutrophils: effects of adenine nucleotides. Clin. Immunol. Immunopathol. 50:30-41.

19. Zigmond, S. H., and J. G. Hirsch. 1973. Leukocyte locomotion and chemotaxis: new methods for evaluation and demonstration of cell-derived chemotactic factor. J. Exp. Med. 173:387-410.

20. Varani, J., M. J. Bendelow, D. E. Sealey, S. L. Kunkel, D. E. Gannon, U. S. Ryan, and P. A. Ward. 1988. Tumor necrosis factor enhances susceptibility of vascular endothelial cells to neutrophil-mediated killing. Lab. Invest. 59:292295

21. Lowe, J. B., L. M. Stoolman, R. P. Nair, R. D. Larsen, T. L. Berhend, and R. M. Marks. 1990. ELAM-1-dependent cell adhesion to vascular endothelium determined by a transfected human fucosyltransferase cDNA. Cell. 63:475-484.

22. Walz, G., A. Aruffo, W. Kolanus, M. P. Bevilacqua, and B. Seed. 1990. Recognition by ELAM-1 of the Sialyl-Le ${ }^{x}$ determinant on myeloid and tumor cells. Science (Wash. DC). 250:1132-1135.

23. Phillips, M. L., E. Nudelman, F. C. A. Gaeta, M. Perez, A. K. Singhal, S.-I. Hakomori, and J. Paulson. 1990. ELAM-1 mediates cell adhesion by recognition of a carbohydrate ligand, Sialyl-Lex. Science (Wash. DC). 250:1130-1132.

24. Warren, J. S., K. R. Yabroff, D. M. Mandel, K. J. Johnson, and P. A. Ward. 1990. Role of $\mathrm{O}_{2}^{-}$in neutrophil recruitment into sites of dermal and pulmonary vasculitis. Free Radical Biol. \& Med. 8:163-172.

25. Bevilacqua, M. P., J. S. Pober, D. L. Mendrick, R. S. Cotran, and M. A. Gimbrone, Jr. 1987. Identification of an inducible endothelial-leukocyte adhesion molecule. Proc. Natl. Acad. Sci. USA. 84:9238-9242.

26. Pober, J. S. 1988. Cytokine-mediated activation or vascular endothelium. Physiology and pathology. Am. J. Pathol. 133:426-433.

27. Graber, N., T. V. Gopal, D. Wilson, L. D. Beall, T. Polte, and W. Newman. 1990. T cells bind to cytokine-activated endothelial cells via a novel, inducible sialoglycoprotein and endothelial leukocyte adhesion molecule-1. J. Immunol. 145:819-830.

28. Picker, L. J., T. K. Koshimoto, C. W. Smith, R. A. Warnock, and E. C. Butcher. 1990. ELAM-1 is an adhesion molecule for skin-homing T cells. Nature (Lond.). 349:796-799.

29. Cotran, R. S., M. A. Gimbrone, Jr., M. P. Bevilacqua, D. L. Mendrick, and J. S. Pober. 1986. Induction and detection of a human endothelial activation antigen in vivo. J. Exp. Med. 164:661-666.

30. Munro, J. M., J. S. Pober, and R. S. Cotran. 1989. Tumor necrosis factor and interferon-gamma induce distinct patterns of endothelial activation and associated leukocyte accumulation in skin of Papio anubis. Am. J. Pathol. 135:121133.

31. Barker, J. N. W. N., R. S. Mitra, C. E. M. Griffiths, V. M. Dixit, and B. J. Nickoloff. 1991. Keratinocytes as initiators of inflammation. Lancet. 337:211214. 